\title{
FORMAÇÃO DO ENGENHEIRO NAVAL ORIUNDO DA ESCOLA NAVAL: O CONVÊNIO MARINHA DO BRASIL E ESCOLA POLITÉCNICA DA UNIVERSIDADE DE SÃO PAULO
}

\section{THE TRAINING OF NAVAL ENGINEER COMING FROM NAVAL SCHOOL: THE BRAZILIAN NAVY AGREEMENT AND POLITECHNICAL SCHOOL OF THE UNIVERSITY OF SÃO PAULO}

\section{H. G. HONORATO ${ }^{1, *}$ and H. C. A. GUIMARÃES ${ }^{2}$}

${ }^{1}$ Escola Superior de Guerra, Departamento de Estudos, Rio de Janeiro, RJ, Brasil

${ }^{2}$ Centro de Coordenação de Estudos da Marinha em São Paulo, Departamento de Administração, São Paulo, SP, Brasil

${ }^{*}$ Corresponding author. Escola Superior de Guerra, Departamento de Estudos, Rio de janeiro, RJ, Brasil, Phone: +55 21999856244

e-mail addressl: hghhhma@gmail.com (H. G.. Honorato).

\section{A R T I C L E I N F O}

Article history:

Received 2018-09-17

Accepted 2018-09-28

Available online 2018-10-31

palavras-chave

Corpo de Engenheiros da

Marinha

Engenharia Naval

Formação do Engenheiro

Naval

Memória

keywords

Marine Corps of Engineers

Naval Engineering

Memory

\section{A B S T R A C T}

The objective of this study is to present the existing agreement between the Brazilian Navy and the Polytechnic School of the University of São Paulo, begun in 1957, for the formation of Naval Engineers from the military superior degree offered by the Naval School. The approach of this research is qualitative, with documentary and bibliographic research and a poll questioning was presented to the students of the third and fourth years whether they already intend to pass to the Engineers Corps. In the analysis of the instrument of data collection it was verified the interest of nine percent of the student in trying the internal competition to graduate in Engineering, a number considered expressive and in consonance with the planning of the personnel sector of the Navy. This important agreement, whose main purpose is to form Naval Engineers capable of researching, designing, constructing and repairing naval and merchant resources may stimulate our naval industry to produce innovative and technological actions.

R E S U M O/R E S U M E N

O objetivo deste estudo é apresentar o convênio entre a Marinha do Brasil e a Escola Politécnica da Universidade de São Paulo, iniciado em 1957, para a formação de Engenheiros Navais oriundos da graduação superior da Escola Naval. A abordagem desta investigação é qualitativa, com pesquisa documental e bibliográfica e uma enquete aos discentes do terceiro e quarto anos questionando se já tencionam passar para o Corpo de Engenheiros. Na análise dos dados verificou-se o interesse de nove por cento do alunado em tentar o concurso interno para se graduar em Engenharia, número considerado e em consonância com o planejamento do setor de pessoal da Marinha. Este importante convênio cuja finalidade precípua é formar Engenheiros Navais capazes de pesquisar, projetar, construir e reparar os meios navais e mercantes, estimula a nossa indústria naval a produzir ações de caráter inovador e tecnológico. 


\section{INTRODUÇ̃̃̃O}

"A construção naval é a base do Poder Marítimo. Todas as nações que se tornaram fortes no mar desenvolveram preliminarmente, de modo notável, a sua indústria naval". (Almirante Carlos Auto Andrade)

A competição da Era Industrial se transformou na competição da Era da Informação e Globalização. Verificamos que estamos imersos em um mundo de rápidas mudanças em diversos contextos, principalmente motivadas pela chamada revolução das tecnologias de informação e conhecimento, advindas em especial da grande rede e dentro de uma sociedade complexa e diversificada. $\mathrm{O}$ homem plural, dentro desse meio incerto e globalizante, procura crescer e buscar sua melhor formação, instrumentalizando sua transformação social.

Um dos autores deste estudo, como professor da Escola Naval (EN), instituição de ensino superior da Marinha do Brasil (MB), procurava questionar os seus alunos quanto a sua futura escolha na carreira militar, em que eles iriam se especializar, visto que esta Instituição de Ensino Superior (IES) militar tem como missão formar os oficiais da MB bacharéis em Ciências Navais para os postos iniciais da carreira, nos Corpos (coletivo de militares da MB com determinada formação profissional) da Armada, de Fuzileiros Navais e de Intendentes da Marinha, sem uma especialização específica. Alguns discentes deixavam claro que a sua opção, mesmo antes de iniciarem a sua graduação, seria a Engenharia, formação esta não prevista no portfólio acadêmico-profissional da EN.

A inquietação deste autor ficou exposta ao se colocar o desejo de um grupo significativo do seu alunado com uma profissão além do que estavam se graduando. A partir deste ponto, desvela-se a figura do Engenheiro, um profissional que surge da prática laboral do conhecimento científico.

Assim inicialmente exposto, o objetivo deste estudo é apresentar o convênio existente na formação dos Engenheiros Navais oriundos da graduação superior militar ofertada pela EN, comparando os pontos convergentes do perfil do profissional engenheiro, de acordo com as Diretrizes Curriculares do Ministério da Educação (BRASIL, 2002), e o que está descrito no currículo de formação do Oficial da Marinha e o seu no perfil desejado (ESCOLA NAVAL, 2017).

A abordagem desta investigação é de cunho qualitativo, com pesquisas documental e bibliográfica como técnicas exploratórias iniciais, com as quais se buscou estabelecer, em especial, a relação sexagenária do convênio com a Escola Politécnica da Universidade de São Paulo (USP), a partir de agora Poli, onde uma parcela dos nossos Engenheiros Navais é graduada quando oriunda da EN. A escolha da pesquisa qualitativa teve como escopo a ênfase na interpretação, "na compreensão das motivações, culturas, valores, ideologias, crenças e sentimentos que movem os sujeitos, que dão significado à realidade estudada e não aos fatos observáveis e passíveis de serem medidos estatisticamente" (IVENICKI; CANEN, 2016, p.11). Conforme esses mesmos autores, a análise documental é um exemplo da metodologia qualitativa, onde este pesquisador mergulhou sobre fontes escritas e as interpretou. Como metodologia empírica, optou-se por apresentar aos discentes do terceiro e do quarto anos da EN uma enquete com uma pergunta direta, na qual se questionava se já pretendiam ou não passar para o Corpo de Engenheiros da Marinha (CEM), ou se ainda estavam com dúvidas sobre sua futura formação. Complementando esta pergunta fechada, uma questão em aberto sobre a sua motivação para tal decisão, ainda na fase de sua graduação militar naval.

Este estudo só aborda os Engenheiros Navais oriundos do convênio da MB com a Poli, não se aprofundando nas formações via Instituto Militar de Engenharia (IME) e Instituto Tecnológico da Aeronáutica (ITA). Espera-se que este estudo seja relevante em apresentar o Convênio $\mathrm{MB}$ e Poli e diagnosticar as relações de confluências entre os perfis dos engenheiros formados em IES civis e dos oficiais oriundos da $\mathrm{EN}$, futuros Engenheiros.

\section{O ENGENHEIRO NO BRASIL E O ENGENHEIRO NAVAL DA MB}

O escopo desta seção é apresentar uma breve história da Engenharia no Brasil, sua origem, a formação acadêmica do profissional, o Engenheiro Militar e o Civil, a construção naval brasileira e a importância dos Engenheiros Navais para o progresso nacional; ao final entraremos no perfil desejado do Engenheiro de acordo com as Diretrizes Curriculares e o meio empresarial.

\subsection{Breve História}

Com o advento da divisão do mundo novo entre espanhóis e portugueses pelo Tratado de Tordesilhas e de Santo Idelfonso, no século XVIII, e como medida de segurança, foram intensificadas as construções fortificadas ao longo dessa linha imaginária, como também em nossa costa, visto termos uma fronteira marítima de $8500 \mathrm{~km}$. Para tais construções foram utilizados engenheiros militares recrutados nas academias militares portuguesas ou no estrangeiro. Segundo Faria (1993, p.137), "o engenheiro militar continuaria a ser ao longo do século XVIII, 'o generalista que sempre fora, homem dos mil ofícios não especificados"”.

O ensino regular de Engenharia no país veio em 1810 por intermédio da criação da Academia Real Militar de Engenharia e Artilharia. Existe, porém, uma discussão sobre a verdadeira data do início formal dos cursos de Engenharia no Brasil, se foi em 1792 e não em 1810, com a criação da Real Academia de Artilharia, Fortificação e Desenho (CUNHA, 1999 apud LAUDARES; PAIXÃO; VIGGIANO, 2009; TELLES, 1994). O surgimento desse ensino formal foi motivado em atender aos objetivos militares, e seus "cursos eram voltados para as classes mais favorecidas e formavam um profissional voltado para a ocupação de cargos com poder de mando [...] um ensino teórico e enciclopédico" (CARVALHO, 2014, p.53). Anteriormente havia cursos regulares de Engenharia no formato de aulas isoladas.

Santos e Silva (2008) apresentam que, por intermédio do Decreto 2.116, de 1o de março de 1858, o Ministro da Guerra à época, Jerônimo Coelho, criou a Escola Central do Exército no Brasil, que deveria ser a responsável pelo curso de Engenheiro Civil, que até então não existia no país. Nota-se o início da desvinculação da formação do engenheiro com as atividades 
militares por intermédio do Decreto Imperial no 5.600, de 25 de abril de 1874, a Escola Central foi transformada em Escola Politécnica do Rio de Janeiro, "voltada exclusivamente para o ensino das Engenharias e subordinada a um ministro civil" (TELLES, 1994, p.23).

Os cursos de Engenharia no Brasil inicialmente também eram voltados para a infraestrutura urbana, o transporte, a defesa e a energia. Carvalho (2014, p.52) assevera que "os cursos de Engenharia vêm sofrendo transformações e evoluções constantes e de forma cada vez mais veloz". Do início militar, passando pela engenharia civil, e, com o advento do avanço científico e tecnológico, se chega à estimativa de 61 áreas de atuação do profissional engenheiro. Segundo dados do Inep, os cursos de Engenharia surgem de acordo com a demanda do mercado, existindo na atualidade 44 modalidades de cursos (SANTOS; SILVA, 2008).

\subsection{A construção naval e a importância do trabalho dos Engenheiros Navais}

Os primeiros estaleiros construídos em terras do Brasil datam do século XV e eram basicamente localizados nas duas primeiras capitais, as cidades mais importantes da colônia, Rio de Janeiro e Bahia. Como importante fato histórico da construção naval inicial no Brasil, podemos citar a passagem do Príncipe Regente Dom João, quando da transferência da Família Real de Portugal em 1808, pela Capitania da Bahia; o então governador, João Saldanha da Gama de Melo Torres Guedes de Brito, o Conde da Ponte, determinou que o Arsenal da Marinha daquela capitania construísse uma embarcação, que ficou conhecida como a "Galeota Imperial" (vide Figura 1), ficando pronta dez anos mais tarde, tendo sido presenteada a D. João VI por ocasião de sua coroação em 1818 (CUNHA, 1978 apud COELHO, 2009).

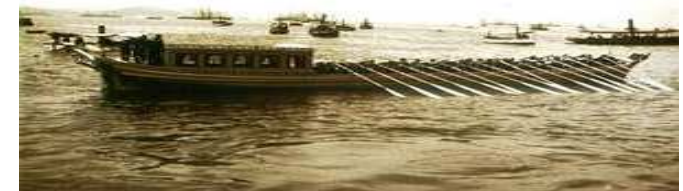

\section{Figura 1 - Galeota de Dom João VI \\ Fonte: Disponível <https://pt.wikipedia.org/wiki/Galeota_de_D._João_VI>. Acesso em: 31 mar. 2018.}

O objetivo principal do início da construção naval era o de "restaurar as embarcações em trânsito com a Europa ou com a finalidade de construir navios para ampliar o comércio e auxiliar a defesa da colônia.”. (SAES; CYTRYNOWICZ, 2007, p.11).

Em agosto de 1825 foi lançada ao mar a Corveta "Campista", projetada pelo primeiro construtor brasileiro, como eram conhecidos os profissionais à época graduados em construção naval oriundos do Arsenal, Primeiro-Tenente José dos Santos Primeiro. Saes e Cytrynowicz (2007, p.17) deixam claro que "outro problema para o desenvolvimento da indústria naval no período imperial era a inexistência de uma escola especializada no aprendizado e na pesquisa das técnicas de construção naval". Os responsáveis pela construção das embarcações eram antigos operários que aprendiam o ofício em aulas de geometria e desenho no Arsenal e na prática com os mestres e construtores.

A solução estratégica do império brasileiro para a formação de um embrião de construtores navais foi o envio de jovens oficiais da Marinha e de civis para se graduarem, tanto nos Estados Unidos quanto na Europa, e os custos envolvidos eram suportados pala fazenda pública.

A Guerra do Paraguai foi o maior conflito armado que ocorreu na América do Sul e, por isso, o foco sempre estava direcionado para as sucessivas batalhas que ocorreram nesse período. Este conflito teve duração de seis anos (1864-1870) e exigiu do Brasil um intenso esforço de construção naval para que fossem defendidos seus interesses na região. A Armada Brasileira possuía o Arsenal de Mato Grosso, localizado na ilha de Cerrito, o qual realizou a manutenção nos navios sem necessidades de grandes deslocamentos. Este Arsenal construiu, em 1863, uma canhoneira a vapor de rodas e, em 1864, um modelo idêntico, entretanto, fluvial.

O Brasil já possuía navios de propulsão mista a hélice, porém eles eram construídos na França e na Inglaterra. Em 1858, o núcleo da esquadra brasileira era constituído por duas canhoneiras francesas e sete inglesas que realizavam a proteção do tráfego marítimo ao longo da costa. Contudo, eram alvos fáceis na guerra contra o Paraguai por possuírem maior porte e calado, sendo assim inadequados para as operações fluviais. Ao final da Guerra da Tríplice Aliança, o "Brasil modernizou seus navios da frota oceânica, inclusive com a aquisição de embarcações no exterior, e ao mesmo tempo aprimorou a construção de vasos nos estaleiros locais, substituindo os meios mais antigos". (ARAÚJO, 2015, p.11).

Em consonância com a reconhecida necessidade de mão de obra qualificada para proporcionar um desenvolvimento a nossa indústria de construção naval, reconhecida nas ações de combate, Joaquim Raimundo de Lamare, oficial da Armada Imperial, quando assumiu a pasta da Marinha, percebeu que seria importante o envio à Europa de Napoleão João Batista Level (Figura 2 - "O Construtor Naval”), em especial à França, e Henrique Antônio Batista, este para a Inglaterra, ambos oficiais da Marinha, para um levantamento a respeito dos avanços da indústria naval. Araújo (2015, p.12) afirma que o foco "era dotar a Marinha de meios que pudessem garantir a integridade do Império, sobretudo nas águas do Prata".

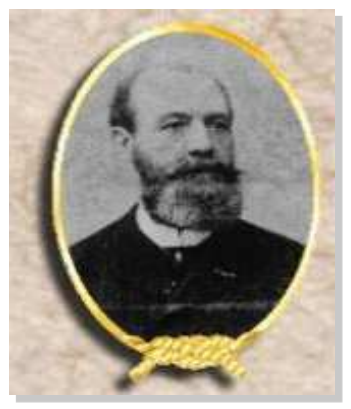

Figura 2 - Napoleão João Batista Level

Fonte: Disponível em: <https://ilheus.wordpress.com/2009/01/29/napoleo-level-oconstrutor-naval/>. Acesso em: 30 mar. 2018. 


\subsection{O ser Engenheiro: os conceitos envolvidos e o perfil desejado}

Ao pensarmos numa profissão ligada à área das ciências exatas, nos vem à mente como primeira e quase imediata reposta: Engenharia. Então, o que significa ser Engenheiro?

Segundo o Novo Dicionário Aurélio da Língua Portuguesa (FERREIRA, 1986, p.654), o Engenheiro é o "indivíduo diplomado em engenharia e/ou profissional dessa arte". Assim, o que seria Engenharia? Essa mesma fonte afirma que é "Arte de aplicar conhecimentos científicos e empíricos e certas habilitações específicas à criação de estruturas, dispositivos e processos que se utilizam para converter recursos naturais em formas adequadas ao atendimento das necessidades humanas".

O termo em si, Engenheiro, tem sua origem na palavra ingenium, que significa engenho ou habilidade, sendo aplicado pela primeira vez na Itália. Machado e Luz (2013, p.35) asseveram que "no século XVIII esta designação passou a ser utilizada para identificar aqueles que utilizam técnicas com base em princípios científicos. Além disso, este termo designava aqueles que se dedicavam ao invento e à aplicação de engenhos.". Segundo o Conselho Federal de Engenharia e Agronomia (CONFEA), o conceito de engenheiro é bem simples: "o profissional que exerce a prática de Engenharia", cuja regulamentação profissional foi contemplada na Lei no 5.194, de 24 de dezembro de 1966 (BRASIL, 1966).

O perfil do engenheiro tem sofrido alterações, de um indivíduo que era prático, aprendiz dos mais experientes, para um profissional com expertise em cálculos matemáticos e solucionador de problemas, e agora "um profissional cidadão com habilidades, competências e atributos que o tornem capaz de atender as exigências atuais, como um projetista de soluções de problemas multidisciplinares e complexos" (MEDEIROS, 2015, p.28). Nose e Rebelatto (2001), em seu estudo para identificar as principais atitudes, habilidades e conhecimentos que as empresas estão desejando do profissional de Engenharia, diagnosticam que este deve ser: (i) indivíduo comprometido com a qualidade do seu serviço; (ii) hábil para trabalhar em equipes multidisciplinares; (iii) hábil para conviver com mudanças; (iv) portador de conhecimentos sólidos das ciências básicas, para a compreensão das novas tecnologias; e (v) com capacidade empreendedora e de liderança.

\section{O CONVÊNIO MARINHA DO BRASIL E UNIVERSIDADE DE SÃO PAULO}

Como o escopo deste estudo é a Engenharia Naval e em especial o convênio entre MB e a Poli, no momento em que este acordo de formação acadêmica está completando 62 anos de sucesso reconhecido, como enfatiza Bittencourt (2006 apud AMARAL, 2013, p.99), “foi de extrema relevância o estabelecimento de um curso superior em engenharia naval no país, e em especial para a Marinha, pois gerou reflexos, principalmente, nos anos 1970, com a nova política de construções navais militares no Brasil”.

Até 1950 não havia no Brasil um curso de formação de Engenheiros Navais, independente de sermos um país com um mar territorial considerado e que tem cerca de $90 \%$ do seu comércio nacional e internacional via os portos nacionais. $\mathrm{Na}$ história da formação do profissional Engenheiro na Marinha, havia como instituições acolhedoras o King'sCollege na Inglaterra, o Massachusetts Instituteof Technology (MIT) e a Universidade de Michigan nos Estados Unidos. Porém, como afirma o Contra-Almirante Luiz Fernando Palmer Fonseca, Diretor de Ensino da Marinha, "a quantidade desses profissionais então disponível não atendia à necessidade da nossa Força e, muito menos, à do País" (SAES; CYTRYNOWICZ, 2007, p.7).

Com essa situação verificada, conforme afirma ainda esse Diretor, foi criada uma comissão para estudar e planejar a implementação de um curso que atenderia a todo o Brasil e deveria ser o primeiro passo "para o estabelecimento da indústria de construção naval brasileira, com técnicos adaptados à nossa realidade" (SAES; CYTRYNOWICZ, 2007, p.7). A solução definitiva para o problema da formação desta mão de obra profissional veio da própria Marinha, que patrocinou e providenciou um curso específico de Engenharia Naval, que deveria ser adaptado à realidade brasileira.

A partir desse momento surgiu o Curso de Construção Naval da Poli; porém, uma questão ainda era discutida: por que partir para um convênio com uma IES em vez de criar um instituto próprio, a exemplo do Exército com o Instituto Militar de Engenharia (IME) ou da Força Aérea Brasileira com o Instituto Tecnológico da Aeronáutica (ITA)? O convênio com a Poli foi um modelo original de parceria no País, onde a MB ofereceu uma melhor formação aos discentes do novo curso criado, forneceu professores, financiou a pós-graduação de professores da USP e investiu em equipamentos e laboratórios. A decisão do convênio não foi uma inovação exclusiva da $\mathrm{MB}$, apenas seguiram-se as instruções que eram à época adotadas nos países mais desenvolvidos, onde as marinhas não dispõem de escolas de engenharia próprias (SAES; CYTRYNOWICZ, 2007).

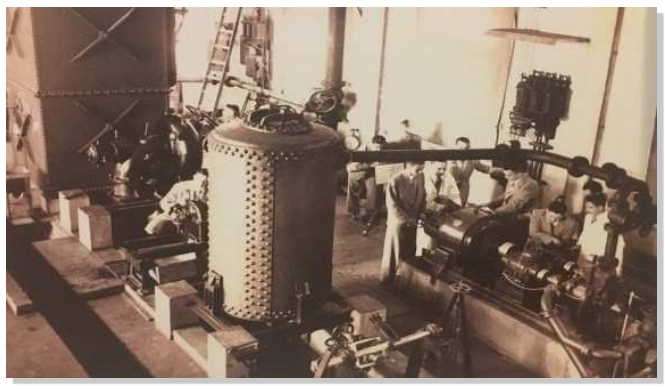

Figura 3 - Laboratório de Hidromecânica da Escola Politécnica, década de 1950 Fonte: Saes e Cytrynowicz (2007, p.56).

O curso de Engenharia foi criado em 1956 e teve seu início oficial em 1957. A Escola Politécnica recebia, além dos alunos civis oriundos do seu concurso de vestibular, oficiais selecionados em um concurso interno e estudantes bolsistas também da Marinha, em um total de 15 vagas por ano. Formouse a primeira turma em 1959, momento em que a nossa indústria naval estava em fase inicial de retomada em seus projetos, em especial com a política desenvolvimentista de Juscelino Kubitschek. Durante a década de 90, o Departamento expandiu suas atividades e incorporou novos temas como engenharia de materiais e tecnologia de exploração de águas profundas. Desde 
1990, o seu nome foi alterado para Departamento de Engenharia Naval e Oceânica1.

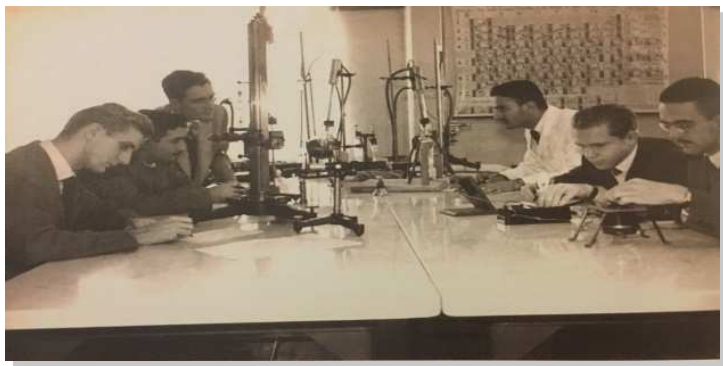

Figura 4 - Alunos da Poliem aula prática no Laboratório de Física no Edifício Santhiago

Fonte: Saes e Cytrynowicz (2007, p.38).

Quando o País estava em franco desenvolvimento na década de 1970, a construção naval brasileira também estava alcançando excelentes patamares, com uma atividade industrial em seus estaleiros em ascensão, com a construção de navios das classes fragatas, corvetas e até de submarinos, quando atingimos o posto, segundo Saes e Cytrynowicz (2007, p.77), “de segundo maior produtor mundial de navios". Ao final, podemos asseverar que, do ponto de vista econômico, não ter uma estrutura própria de formação de Engenheiros Navais, ou mesmo do ponto de vista técnico, quando começou a se formar mão de obra para a construção naval adaptada à realidade nacional, a solução da Marinha não poderia ter sido melhor.

\section{OS FUTUROS ENGENHEIROS NAVAIS ORIUNDOS DA ESCOLA NAVAL}

Esta seção tem como foco o trato específico do Engenheiro que faz a opção pela mudança do Corpo, de Armada e de Fuzileiros Navais, para o CEM, além de apresentar como ocorre esta migração. Outra parcela trata da análise do questionário aplicado aos alunos dos terceiro e quarto anos da EN sobre seu interesse em fazer a opção pelo curso de engenharia.

\subsection{A Carreira do Oficial Engenheiro Naval atualmente}

A indústria de construção naval não apenas projeta e constrói navios mercantes, mas também participa ativamente do processo de modernização e aparelhamento de nossa Marinha. Tal valorização é fomentada pelo Plano de Articulação e Equipamento da Marinha1, com a construção de diversos navios de guerra em estaleiros nacionais; como exemplos temos a previsão de construção de 27 navios patrulhas de 500 toneladas. Não podemos nos esquecer do Programa de Desenvolvimento de Submarinos (PROSUB) com a previsão do lançamento do nosso primeiro submarino nuclear em 2025.

Assim exposto, a construção de um meio operativo é “[...] um complexo projeto de engenharia que envolve inúmeras atividades multidisciplinares, desempenhadas em um grande período que necessita de vultosos aportes de recursos" (AMARAL, 2013, p. 20). Não devemos nos esquecer da formação de engenheiros com a competência desejada para que o país mantenha e desenvolva, em especial, “[...] sua capacidade de projetar e de fabricar tanto submarino de propulsão convencional como de propulsão nuclear" (BRASIL, 2008, p.13).

A entrada para o CEM dar-se-á de duas formas: por concurso público de profissionais já graduados em IES, com uma média de aprovados da ordem de 60 engenheiros por ano, ou por concurso interno de militares oriundos da EN com o preenchimento de dez vagas anuais, distribuídas nas seguintes Engenharias: Naval, Mecatrônica, Armamento, Mecânica Aeronáutica e Aeronáutica. Ou seja, apenas $15 \%$ dos Engenheiros serão oriundos da EN. A tabela 1 mostra a necessidade anual de profissionais oriundos da EN e que farão o curso no convênio da MB com a Poli, no caso específico das habilitações em Naval e Mecatrônica. As formações em Aeronáutica e Mecânica Aeronáutica são no ITA, e em Armamento, no IME.

Tabela 1 - Admissão por Cursos de Graduação em Engenharia para Oficiais do CA e FN.

\begin{tabular}{llllll} 
Habilitação & $\mathbf{2 0 2 0}$ & $\mathbf{2 0 2 1}$ & $\mathbf{2 0 2 2}$ & $\mathbf{2 0 2 3}$ & $\mathbf{2 0 2 4}$ \\
\hline Eng. Aeronáutica & 1 & 1 & 1 & 1 & 1 \\
Eng. Armamento & 1 & 1 & 1 & 1 & 0 \\
$\begin{array}{l}\text { Eng. Mecânica } \\
\text { Aeronáutica }\end{array}$ & 1 & 1 & 1 & 1 & 1 \\
$\begin{array}{l}\text { Eng. } \\
\text { Mecatrônica }\end{array}$ & 1 & 0 & 1 & 0 & 1 \\
Eng. Naval & 6 & 7 & 6 & 7 & 7 \\
\hline Totais & $\mathbf{1 0}$ & $\mathbf{1 0}$ & $\mathbf{1 0}$ & $\mathbf{1 0}$ & $\mathbf{1 0}$ \\
\hline
\end{tabular}

Ambos os concursos são realizados anualmente sob a responsabilidade do Centro de Coordenação de Estudos da Marinha em São Paulo (CCEMSP), que fica localizado na própria USP. O CCEMSP tem como missão coordenar o esforço de integração da MB com as indústrias, Instituições de Ensino Superior e de Pesquisas no estado de São Paulo, em áreas acadêmicas, científicas e tecnológicas. O calendário para o concurso interno de admissão aos cursos de graduação em Engenharia, cuja sigla é CA-EngNav, já está aprovado e divulgado para o próximo ano, tendo como início do processo o dia 16 de abril de 2018. As provas desse concurso são elaboradas por professores da Poli nas seguintes disciplinas: Matemática I e II, Mecânica I e II e Eletricidade I e II. O processo todo deverá estar concluído até 31 de agosto.

No último concurso realizado foram 30 inscritos e 12 aprovados, sendo apenas dez classificados. A preparação desses oficiais para o concurso é realizada durante o seu período de graduação na EN, com disciplinas como Cálculo I e II, Mecânica (Geral, de Navio), Eletricidade, Eletrônica (digital e aplicada), entre outros conteúdos distribuídos no curso de formação de oficial.

No período compreendido entre os anos de 2003 a 2017 foram graduados 40 Engenheiros Navais plenos. Como determinado pela Alta Administração da MB, que trata das necessidades da força de trabalho para comporem as formações necessárias ao CEM, foram formados na Poli no mesmo período dois Engenheiros Mecânicos e quatro em Mecatrônica. 
No currículo da EN estão previstos, em sua sinopse geral do curso de graduação (ESCOLA NAVAL, 2017), perfis comuns desejados para os seus egressos. Em relação ao foco deste estudo e conforme o que foi apresentado no perfil ideal de um Engenheiro, podemos pinçar as seguintes competências e habilidades: (i) liderar equipes na realização de tarefas técnicas; (ii) descrever os princípios básicos e as aplicações dos conceitos dos fenômenos físicos, mecânicos, elétricos e magnéticos relativos aos meios navais; (iii) identificar os princípios que regem o equilíbrio e o escoamento dos fluidos sob ação das forças; (iv) deverá possuir, ainda, o contínuo aperfeiçoamento profissional, sujeito, cada vez mais, a transformações velozes e sofisticadas; e (v) ser capaz de acompanhar a evolução do mundo contemporâneo e do Brasil.

\subsection{Análise da coleta de dados}

Conforme já comentado, a metodologia deste estudo contou com um pequeno questionário com apenas uma pergunta, dividida em duas partes. A primeira parte era direta, se havia a pretensão de passar para o CEM, com três opções de resposta: "sim", "não" e "estou com dúvida". Ato contínuo e após esta questão suscitada, os sujeitos deste estudo poderiam justificar a sua resposta. Estes eram os alunos dos dois últimos anos da graduação da Escola Naval, dos Corpos da Armada e de Fuzileiros Navais, que, como segundos-tenentes, poderiam prestar o concurso para cursarem Engenharia Naval na Poli ou mesmo em outra IES no campo da Engenharia, especialmente no ITA e no IME.

Com o escopo de garantir o sigilo da fonte, os respondentes foram assinalados com um código alfanumérico da seguinte forma: "S" para quem respondeu sim; "N" para o não; e "D" para os alunos ainda com dúvida. Segue-se após a letra uma numeração sequencial e aleatória, S1, N130 ou D10, como exemplos. As justificativas que deram sustentação ao objetivo deste estudo foram pinçadas e transcritas, seguindo-se conclusões possíveis.

A tabela 2 mostra o total de alunos componentes das turmas do terceiro e do quarto anos de 2017 e os que efetivamente responderam o questionário, sendo divididos conforme a questão submetida.

Tabela 2 - Total de Aspirantes respondentes em relação ao total de discentes.

\begin{tabular}{llll} 
Totais & Respondente & Alunado & \% Retorno \\
CA & 275 & 285 & $96 \%$ \\
FN & 71 & 72 & $99 \%$ \\
\hline Totais & $\mathbf{3 4 6}$ & $\mathbf{3 5 7}$ & $\mathbf{9 7 \%}$ \\
\hline
\end{tabular}

$\mathrm{Na}$ tabela 3 podemos verificar o quantitativo de respostas com "sim", "não" ou "estou em dúvida". Uma constatação imediata é a dos Aspirantes do Corpo de Fuzileiros Navais (FN) em que apenas um discente pretende fazer o concurso para o CEM e, ao lermos todas as respostas deste grupo de alunos, principalmente os do último ano da graduação, podemos resumir na seguinte frase do N30: "o único motivo de ter entrado para a MB foi para ser do Corpo de Fuzileiros Navais”. Uma afirmação interessante expõe o pensamento do jovem militar, “[...] não me agrada este tipo de formação, pois prefiro trabalhar mais com pessoas do que com projetos" (N22). Poderíamos pinçar outras respostas, mas é patente a não identificação daqueles que responderam "Não" com a futura profissão de engenheiros, pois, neste caso e a princípio, estão satisfeitos de pertencerem ao CFN.

Tabela 3 - Total de respondentes por opção de resposta.

\begin{tabular}{lllll} 
& & & & $\%$ \\
Totais & FN & CA & Totais & Respostas \\
Sim & 01 & 30 & 31 & $9 \%$ \\
Não & 62 & 188 & 250 & $72 \%$ \\
Dúvidas & 08 & 57 & 65 & $19 \%$ \\
\hline Totais & 71 & 275 & 346 & $100,00 \%$ \\
\hline
\end{tabular}

Continuando a análise da tabela 4 , poderemos verificar que 31 Aspirantes pretendem fazer o concurso para o CEM, ou seja, $9 \%$ do total de discentes. Se formos também considerar os que estão com dúvidas, teríamos cerca de $30 \%$ dos discentes, o que poderemos inferir que já havia uma pré-condição quando da entrada para a EN de ser Engenheiro e sua via de entrada para a formação seria pela MB.

Foram separadas e lidas todas as 31 respostas "Sim", pelas quais podemos constatar que, em sua grande maioria, os respondentes deixam claros: (i) a identificação com a área tecnológica; (ii) a facilidade com as disciplinas ligadas à área de exatas integrantes do currículo da EN; (iii) o desejo de ser engenheiro mesmo antes de entrar para a Marinha; (iv) uma oportunidade na carreira, ótima formação acadêmica e poucos navios operando; (v) uma carreira desafiadora e gratificante; (vi) o interesse em possuir maior mercado de trabalho após a reserva; e (vii) vontade de se tornar docente no futuro, ser do quadro do magistério da Marinha.

O Aspirante S28 apresentou a sua situação particular, pois se encontrava estudando em uma faculdade de Engenharia no meio civil, ele observou que o engenheiro é um profissional capaz de fazer com que as soluções sejam idealizadas em um cenário onde não há solução visível. Continuando com seus argumentos, esse discente complementa: "Alinhado ao sonho de honrar a Pátria sob qualquer cenário, tenho a intenção de ser Engenheiro Naval e poder participar com toda dedicação possível ao desenvolvimento tecnológico nacional, principalmente nas Forças Armadas.”. S28 é um dos criadores do Grêmio de Ciência e Tecnologia da Escola Naval (GCTEN) e pretende incentivar os demais integrantes da instituição sobre a importância do desenvolvimento tecnológico para a Marinha.

Podemos verificar da leitura das justificativas de todos os Aspirantes do $3^{\circ}$ e do $4^{\circ}$ anos que existe uma tendência de se pensar no futuro profissional, mesmo quando ainda não formados. O não pensamento de escolha de formação ou especialização posteriormente não vem à baila, em sua maioria a escolha pela formação do ser Marinheiro em síntese permanece, pois todos estão preocupados com a sua melhor 
formação acadêmica, o que já justifica a entrada por concurso público para a graduação no ensino superior militar, no caso em estudo, na EN.

\section{CONSIDERAÇÕES FINAIS}

No contexto histórico apresentado sobre a criação das instituições de formação do Engenheiro no Brasil colônia até os dias atuais, apresentamos conceitos sobre o termo designativo da profissão que reforçam a ideia de alguém com formação técnica profissional, generalista, crítica, com a capacidade de desenvolver novas tecnologias de forma criativa e com o escopo na resolução de problemas, preocupado com o meio ambiente e a sustentabilidade. Ao relacionarmos ao perfil também desejado do oficial que é formado pela $\mathrm{EN}$, fruto verde do futuro Engenheiro da Marinha do Brasil, e o previsto no referencial estudado, podemos verificar que ambos trazem como ação formadora importante a habilidade de liderança, atualmente reforçada para uma sociedade de rápidas e complexas mudanças, em especial nas relações de trabalho.

Somos um país continente com um vasto mar territorial, onde a MB é a responsável por assegurar os meios navais necessários para negar o uso do mar aos inimigos que venham a ameaçar o Brasil por vias marítimas, além de controlar águas interiores e realizar projeção de poder sobre terra, caso necessário. Para atender os seus objetivos a MB deve manter aparelhada e expandir a sua Esquadra, seja adquirindo novos meios de outros países seja através de projetos e construções no país. Só para relembrar, até 1957 não tínhamos profissionais formados em Engenharia Naval e nem uma construção naval realmente brasileira.

$\mathrm{Na}$ análise do instrumento de coleta de dados aplicado aos futuros oficiais da Marinha dos Corpos da Armada e de Fuzileiros Navais, aqueles que podem optar pela mudança para o CEM por intermédio de concurso interno, podemos verificar que nove por cento do alunado vai tentar o concurso e, se passar e se classificar no número de vagas estipuladas pelo setor de pessoal da MB, comporá um grupo de cerca de 10 cursantes por ano; serão Engenheiros Navais que participarão dos estudos e projetos futuros de uma Marinha para o século XXI, que tem a sua força no PROSUB como menina dos olhos, a construção e o lançamento ao mar do submarino de propulsão nuclear previsto para 2025.

O importante e sexagenário convênio da MB com a Poli tem a finalidade precípua de formar Engenheiros Navais, militares e civis, capazes de pesquisar, projetar, construir e reparar os meios navais e mercantes, estimulando a nossa indústria naval a produzir ações de caráter inovador e tecnológico e, no caso da Marinha do Brasil, proteger o nosso mar territorial, salvaguardando o nosso comércio exterior por via marítima, exportadora das riquezas produzidas em nosso País, além de honrar o Patrono do Corpo de Engenheiros Navais, CA (EN) João Cândido Brazil.

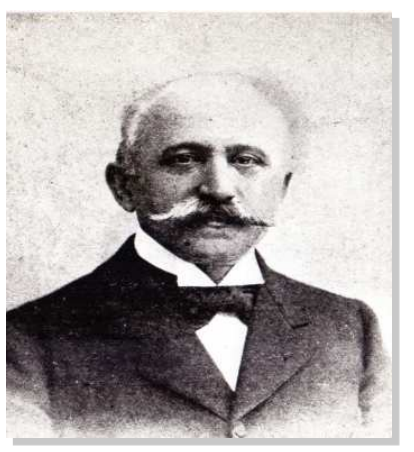

Figura 5 - CA (EN) João Cândido Brazil

Fonte: Disponível em:

<https://www.marinha.mil.br/den/biografia>. Acesso em: 30 mar. 2018.

\section{REFERÊNCIAS}

AMARAL, Misael Henrique Silva do. O poder pelo mar: a indústria de construção naval militar no Brasil a partir da política desenvolvimentista de Juscelino Kubitschek (1959-1961).2013, 166f. (Dissertação mestrado em História Política e bens culturais) Fundação Getúlio Vargas, Rio de Janeiro, 2013.

ARAÚJO, Jony Santana de. Entre a vela e o vapor, entre a madeira e o ferro: a transição, a construção e a ação dos Ironclads na Marinha Imperial brasileira 18501865. Revista Navigator, Rio de Janeiro, v.1, n.11, p.9-22, 2015.

BRASIL. Ministério da Defesa. Estratégia Nacional de Defesa. Brasília, DF, 2008.

Conselho Nacional de Educação. Resolução CNE/CES 11/2002, aprovada em 11 de março de 2002. Institui as Diretrizes Curriculares Nacionais do Curso de Graduação em Engenharia. Diário Oficial [da] República Federativa do Brasil. Brasília/DF, 25 de fevereiro de 2002. Seção 1, p. 17.

BRASIL. Lei ${ }^{\circ}$ 5.194, de 24 de dezembro de 1966. Regula o exercício das profissões de Engenheiro, Arquiteto e Engenheiro-Agrônomo, e dá outras providências. Diário Oficial [da] República Federativa do Brasil. Brasília/DF, 27 de dezembro de 1966.

CARVALHO, Leonard de Araújo. Competências requeridas na atuação profissional do Engenheiro Contemporâneo. 2014. 109f. Dissertação (Mestrado em Educação Tecnológica) - Centro Federal de Educação Tecnológica de Minas Gerais, Belo Horizonte, 2014.

COELHO, Daniela. Conservação e Restauro de um Objecto Histórico: a Galeota Real de D. João VI. Revista Estudos de Conservação e Restauro. n.1, p.57-72, Porto, Portugal, 2009.

ESCOLA NAVAL. Currículo: curso de graduação de oficiais. Rio de Janeiro, 2017.

FARIA, Miguel Figueira de. A engenharia militar no Brasil setecentista: Cartografia, Urbanismo e Fortificação. In: COLÓQUIO INTENACIONAL "LA COSTRUTIONE DEL NUOVO MONDO”, Anais...Academia Ligusticadi Belli Art, Genova, IT, nov. 1993. 
FERREIRA, Aurélio Buarque de Holanda. Novo Dicionário da Língua Portuguesa, 2.ed, rev. e aum. Rio de Janeiro: Nova Fronteira, 1986.

IVENICKI, Ana; CANEN, Alberto Gabbay. Metodologia da Pesquisa: rompendo fronteiras curriculares. Rio de Janeiro, Ciência Moderna, 2016.

LAUDARES, João Bosco; PAIXÃO, Edmilson Leite; VIGGIANO, AdalciRighi. O ensino de Engenharia e a formação do Engenheiro: contribuição do programa de Mestrado em tecnologia do CEFET-MG. Revista Educação Tecnológica, Belo Horizonte, v.14, n.1, p.60-67, jan./abr. 2009. Disponível em: $<$ https://periodicos.cefetmg.br/index.php/revistaet/article/view/213/212>. Acesso em: 20 dez. 2017.

MACHADO, Walnice Brandão; LUZ, Talita Ribeiro. O engenheiro e as competências necessárias ao desempenho profissional: um estudo de caso em uma IES privada da região metropolitana de Belo Horizonte. Revista E-xacta, Belo Horizonte, v.6, n.2, p.33-44, 2013. Disponível em: <www.unibh.br/revistas/exacta/>. Acesso em: $20 \mathrm{dez}$. 2017.

MEDEIROS, WladmirLauz. Professor-Engenheiro ou Engenheiro-Professor: A construção da identidade do profissional no ensino superior. 2015. 73f. Dissertação (Mestrado em Ciências) - Universidade Federal do Rio Grande. Rio Grande, RS, 2015.

NOSE, Michelle Mike; REBELATTO, Daisy Aparecida do Nascimento. O perfil do Engenheiro segundo as empresas. In: XXIX Congresso Brasileiro de Educação em Engenharia [COBENGE], 19 a 22 dez. 2001. Porto Alegre. Anais...Porto Alegre, 2001. p. 2530.

OLIVEIRA, Vanderlí Fava de et al. Um estudo sobre a expansão da formação em Engenharia no Brasil. Revista de Ensino de Engenharia da ABENGE. Edição Especial comemorativa dos 40 anos da entidade, 2012. Disponível em: <www.ufjf.br/observatorioengenharia/files/2012/01/ ExpEng-RevAbenge.pdf. Acesso em: 20 dez. 2017. ISSN 0101-5001.

SAES, AlexandreMacchione; CYTRYNOWICZ, Roney. Cinquentenário do convênio entre a MB e a USP: a criação do curso de engenharia naval na Escola Politécnica. São Paulo: Narrativa Um, 2007.

SANTOS, Sara Rios Bambirra; SILVA, Maria Aparecida da. Os cursos de engenharia no Brasil e as transformações nos processos produtivos: do século XIX aos primórdios do século XXI. Revista Educação em foco, Belo Horizonte, ano 11, n.12, p.21-35, dez. 2008.

TELLES, Pedro Carlos da Silva. História da Engenharia no Brasil: séculos XVI a XIX. 2. ed. revisada e ampliada. Rio de Janeiro: Clavero, 1994. 